\title{
Dr. Richard C. Nelson: An Important Multigenerational Father of Biomechanics
}

\author{
Robert W. Norman, ${ }^{1}$ Stuart M. McGill, ${ }^{2}$ and James R. Potvin ${ }^{3}$ \\ ${ }^{1}$ University of Waterloo; ${ }^{2}$ Backfitpro Inc; ${ }^{3}$ McMaster University
}

\begin{abstract}
Dr. Richard Nelson is internationally acknowledged in many countries as an extremely important leader in the emergence of biomechanics of human movement as a respected scientific discipline. As his $\mathrm{PhD}$ graduates, and, subsequently, their graduates, have become faculty members at many universities, Dr. Nelson's influence has grown for more than 50 years via several generations of his biomechanics "children." It was probably never known to him that he also had significant influence on all laboratory-based subdisciplines of the undergraduate and graduate education and faculty research programs of the then new (1967) Department of Kinesiology at the University of Waterloo, Canada. The teaching and research programs included not only biomechanics but also exercise and work physiology, anatomy, biochemistry, and neurophysiology of human movement.
\end{abstract}

Keywords: EMG assisted lumbar spine models, EMG filtering, international influence, spine injury/recovery

The Senate of the University of Waterloo approved one of North America's first, if not the first, Department of Kinesiology in 1967. The chair of this new department, Dr. Norman Ashton, convinced the Senate that his concept of kinesiology was a discipline that would be devoted to teaching and research on the science of human movement, in all its forms and dimensions, ranging from cell to society.

The scope of kinesiology at Waterloo has long included factors that produce and control normal, pathological, and highly skilled human movements across the age span. Examples are working, walking, running, jumping, exercising, competitive and workplace lifting, tasks of daily living, sport and work injury mechanisms, assessment and minimization of risk, design of protective equipment, rehabilitation, psychosocial implications, and interventions for workplace change. This scope required undergraduate and graduate teaching and research labs within the Department, not only for biomechanics but also for physiology, biochemistry, cadaver anatomy, and neurophysiology, all part of the new curriculum.

Dr. Nelson's influence on these labs and on young faculty members began with a 1969 visit to Penn State by Norman Ashton and Dr. Robert Norman to discuss the PhD program, lab equipment, and laboratory technical assistance. The visit was suggested by Dr. Peter Stothart, one of Nelson's first PhD graduates. Stothart had joined Dr. Norman in biomechanics at Waterloo. Dr. Norman was hired in 1967, with an MSc, to develop and teach biomechanics courses. At that time, he was the only applicant with a background in math, physics, anatomy, and physiology. He was obliged to earn a doctorate to keep his job.

That visit and Dr. Nelson's generosity allowed Dr. Norman to keep his job at Waterloo for 35 years. More importantly, the department chair, Dr. Ashton, annually spent a lot of base budget money on high-quality lab equipment and full-time technical

Norman and McGill were with the Department of Kinesiology, Faculty of Applied Health Sciences, University of Waterloo, Waterloo, ON, Canada. McGill now heads Backfitpro Inc, Gravenhurst, ON, Canada. Potvin was with the Department of Kinesiology, Faculty of Science, McMaster University, Hamilton, ON, Canada. Norman (norman@uwaterloo.ca) is corresponding author. assistance for undergraduate and graduate teaching and faulty research development in the Kinesiology Department program.

Dr. Nelson's advice contributed immensely to high-quality teaching and research, and high research productivity early in the careers of the young faculty members. The result was high demand by students for entry into the Kinesiology program, and early research publications that resulted in high success in research grant applications that took pressure off base budget money.

Much of the Waterloo biomechanics teaching and research used equipment recommended by Nelson, such as high-speed cameras, film digitizers, EMG recorders, and minicomputers. ${ }^{1}$ Dr. Norman's PhD research, ${ }^{2}$ supervised by Dr. Nelson, included studies of the feasibility of using rectified, digitally filtered surface EMG (sEMG) and elbow joint anatomy to calculate dynamic time histories of individual muscle forces and loading on the joint during flexions, extensions during bidirectional slow, and fast movements (Figure 1). This work was dramatically improved by several generations of Dr. Norman's students. Stuart McGill and James Potvin were students of Norman's in the '70s and '80s-research "grandchildren" of Dr. Nelson.

Dr. McGill expanded Norman's work by developing a highly biofidelic model of the torso, pelvis, and legs, with a detailed focus on the anatomy and mechanics of the lumbar spine. In this way, the movement strategy of the individual was evaluated for skills required to avoid stress concentrations and subsequent injury. While the skeleton is often modeled as an articulated linkage with rigid links, the spine is actually a flexible rod. Special mechanical considerations were required to understand how the flexible spine allows movement for tasks, such as tying one's shoes, but then transforms into a rigid beam to prevent buckling when picking up heavy objects. Early studies of powerlifters revealed how the spine successfully supported well over a ton of compressive load. This led to the development of approaches to quantify spine stability. This was a game changer in understanding that muscles are not arranged simply as agonist and antagonist pairs. All muscles are agonists with the primary goal of ensuring sufficient stability in a complex linkage of segments to perform tasks. Proximal stiffness is a necessary condition within an articulated linkage for distal movement and skilled athleticism. Muscle activation creates both force and stiffness. Appreciation of 




Figure 1 - Robert Norman in 1972 working on the HP2115A computer in the Penn State Biomechanics Lab. (The photo was taken by, then, fellow doctoral student Dr. James Walton.)

this objective function helps explain patterns of muscle activation. In many cases, muscles activate primarily to increase stiffness, not motion. Tuning stiffness in models enabled them to replicate movement and explain how a person can stand upright using stiffness, not force, and how the body controls motion with stiffness.

Dr. McGill's career expanded when Professor Norman (Dean of the faculty at the time) asked him to start an experimental low back pain clinic. This was perhaps the only clinic in the world to follow up with each patient to keep score of outcomes. We learned that there is no such thing as nonspecific back pain-it is all very specific. This motivated investigations to develop novel pain provocation tests by manipulating postures, motions, and loads to move stress from one specific tissue to another. ${ }^{3}$ Tests with high diagnostic specificity were developed and offered to the clinical community through the textbook Low Back Disorders: Evidence-Based Prevention and Rehabilitation. ${ }^{4}$ Members of the lay public were then shown how to perform provocation self-tests to reveal what to do and what not do about their back pain. Each patient in the clinic became a test subject to study. Time and time again, clinical follow-up revealed the power of mechanostimulation to remodel injured tissue, leading injured athletes back to world record performance. For example, elite power lifter Brian Carroll documented his story in the book Gift of Injury. ${ }^{5}$

Professor Nelson was intrigued with sport skill. The final years of S.M.M.'s career expanded as elite athletes came to the university clinic from around the world for back pain issues. The insights into linkage mechanics and muscle, fascia, and connective tissue mechanics helped grow a much better understanding of optimal sport skill. The great athletes were rarely the strongest (powerlifters excluded). Instead, they turned out to have optimized the elastic tuning of their bodies and manipulated stiffness, position, timing, and muscle pulsing to create a system where all muscles became agonists to the skilled performance.

Dr. Potvin is also an academic grandson of Dr. Nelson but, partially, also his great-grandson. He arrived in graduate school at the University of Waterloo in 1986, under the direct supervision of Dr. Norman but just weeks after Dr. McGill successfully defended his doctoral thesis involving the aforementioned spine model. Potvin's master's thesis gave that model a good test run, comparing the muscle and passive tissue contributions to spine mechanics during lifting with a "squat" and "stoop" technique. The stoop lifts were particularly challenging to run in the model given the highly nonlinear response of the supraspinatus and infraspinatus ligaments of the lumbar spine, which were often recruited with the larger spine flexion magnitudes associated with lifting from the floor with the knees less flexed. Dr. Potvin's doctoral work continued under Norman's supervision, but with substantial mentorship from Dr. McGill, and extended the detailed assessment of spine mechanics during lifting under rested conditions to bouts of prolonged and repetitive lifting where muscle fatigue was associated with increased demands on the lumbar spine's passive extensor tissues. Efforts were made to simplify McGill and Norman's spine model and focus on key indicators of muscle contributions to lumbar loading and kinematics, to facilitate the assessment of repetitive lifting tasks being performed continuously for 2 hours. The motion capture and sEMG technology at the time did not allow for the full spine model to be used for those durations.

The challenges of simplifying the complex spine model into a version that would still provide insights to muscle contributions to joint loading and lifting/lowering kinematics was the start of a long research focus for Dr. Potvin, with the goal of refining the use of electromyography to predict muscle force, a continuation of Dr. Norman's work under Dr. Nelson's supervision. The challenge was not just to simplify the model while retaining biological fidelity. Fatigue is notorious for contaminating the relationship between sEMG amplitudes and muscle force, so a solution to that problem became another focus for Potvin. This ultimately led to the discovery that much of the sEMG spectrum was not related to muscle force at all and that extreme high-pass filtering or whitening of the sEMG signal actually improved sEMG-to-force estimates, even with a substantially diminished remaining signal power. ${ }^{6}$ Much of this research, and other contributions described later, were accomplished in collaboration with Dr. Steve Brown, who was supervised by Dr. Potvin for his master's and Dr. McGill for his doctorate, making him a hybrid academic great-grandson and great-great-grandson of Dr. Nelson's. One of the most important aspects of the extreme high-pass filtering is that it removed most of the sEMG power in the low-frequency range, which also happened to be the component of the sEMG spectrum that was most contaminated by fatigue even when force was not changing during sustained isotonic contractions. Thus, this process allowed for sEMG to be used to estimate muscle force even during fatiguing tasks.

Like McGill, Potvin also became very interested in the contribution of individual muscles to lumbar joint stiffness and stability. Potvin and Brown ${ }^{7}$ developed a simple equation to accurately estimate these contributions using only muscle force and muscle origin and insertion coordinates as inputs, based on work by Cholewicki and McGill, ${ }^{8}$ and it was used in a series of experiments to study the changes in trunk muscle contributions to spine stability during sudden loading or unloading perturbations, as well as prolonged isometric and isotonic loading, causing spine flexion, axial twist, or lateral bending moments. Later work included sudden knee flexion perturbations.

Richard Nelson appreciated the "bigger picture." He started an academic family, and his children, grandchildren, greatgrandchildren, and several more generations created an enviable 
bloodline. McGill and Potvin recalled an incident at a North American Congress on Biomechanics at Waterloo in 1998. Dr. McGill chaired a keynote talk by Dr. Nelson on Forensic Biomechanics. At the end, McGill asked all of those who Dr. Nelson had supervised, his biomechanics children, to stand and remain standing. Several stood. Then, he invited students of those standing to stand-Dr. Nelson's biomechanics grandchildren. By the fourth generation, almost everyone, in an audience of nearly 300, was standing! You can imagine the beaming smile on Dr. Richard Nelson's face.

Your fifth generation is emerging, Dr. Nelson. You have left an incredible biomechanics education and research legacy and academic family.

\section{References}

1. Norman R, Komi P. Mechanical energetics of world class crosscountry skiing. Int J Sports Biomech. 1987;3(4):353-369. doi:10. 1123/ijsb.3.4.353
2. Norman RWK. The Use of EMG in the Calculation of Dynamic Joint Torque [PhD thesis]. The Pennsylvania State University; 1977. (Supervisor R.C. Nelson)

3. McGill SM. Back Mechanic: The Step-By-Step McGill Method to Fix Back Pain. Backfitpro Inc.; 2015. www.backfitpro.com.

4. McGill SM. Low Back Disorders: Evidence Based Prevention and Rehabilitation. 3rd ed. Champaign, IL: Human Kinetics; 2016.

5. McGill SM, Carroll B. The Gift of Injury. Backfitpro Inc; 2018. www. backfitpro.com.

6. Potvin JR, Brown SHM. Less is more: high pass filtering to remove up to $99 \%$ of the surface EMG signal power, improves EMG-based biceps brachii muscle force estimates. J Electromyogr Kinesiol. 2003; 14(3):389-399. doi:10.1016/j.jelekin.2003.10.005

7. Potvin JR, Brown SHM. An equation to calculate individual muscle contributions to joint stability. J Biomech. 2005;38(5):973-980. doi: 10.1016/j.jbiomech.2004.06.004

8. Cholewicki J, McGill SM. Mechanical stability of the in vivo lumbar spine: implications for injury and chronic low back pain. Clinical Biomech. 1996;11(1):1-15. doi:10.1016/0268-0033(95)00035-6 